\title{
An Empirical Analysis of Potential Cyclist Injuries and Cycling Outfit Comfort
}

\author{
YW Teyeme ${ }^{1,2 *}$, B Malengier ${ }^{1}$, Tamrat Tesfaye ${ }^{2}$, Maria-Cristina Ciocci ${ }^{3}$, S Vasile ${ }^{4}$ and L Van Langenhove ${ }^{1}$ \\ ${ }^{1}$ Department of Materials, Textiles and Chemical Engineering, Faculty of Engineering and Architecture, Ghent University, Belgium \\ ${ }^{2}$ Ethiopian Institute of Textile and Fashion Technology (EiTEX), Bahir Dar University, Ethiopia \\ ${ }^{3}$ Department of Mathematics: Analysis, Logic, and Discrete Mathematics, Faculty of Sciences, Ghent University, Belgium \\ ${ }^{4}$ Department of Fashion, Textiles and Wood Technology, University College Ghent, Belgium
}

*Corresponding author: YW Teyeme, Department of Materials, Textiles and Chemical Engineering, Faculty of Engineering and Architecture, Ghent University, Belgium.

Received Date: October 31, 2019

Published Date: November 05, 2019

\begin{abstract}
This study investigated the relationship between pain/injury and training characteristics in cyclists. In addition, ergonomic wear comfort of their garments was investigated. A total of 94 complete questionnaire responses were analyzed. The result indicated that lower back pain was the most prevalent injury causing the highest rates of functional damage and medical attention. The injury level of cyclists was affected by the cluster with elite cyclists reporting pain while cycling. Many cyclists were not very satisfied with the comfort level of their current outfit, $39 \%$ of respondents were experienced with different discomfort sensations. The most frequent causes of discomfort were thermal and moisture discomfort sensation related to fabric characteristics. Moreover, design and fit of the garment were considered as cause of discomfort next to thermal discomfort sensation. Therefore, it could be concluded that garments that have good ventilation or breathability and very good fit values were preferred by cyclists. Design, limited choice (availability), appearance/look and quality were the main reason for their brand selection preferences.
\end{abstract}

Keywords: Cycling; Injury; Pain; Training characteristics; Cycling outfit; Comfort

\section{Introduction}

Cycling has become one of the world's most popular sports in recent years. But its increasing popularity has also resulted in a growing number of injuries. Cycling is an endurance activity often requiring long bout with a spinal forward flexion posture. Because of its prolonged repetitive nature of the activity, riding a bike becomes a challenging activity. Moreover, cyclists are known to be vulnerable to low back pain.

Cycling is an endurance sport often requiring long bouts with a prolonged spinal forward flexion posture. Because of its prolonged repetitive nature of the activity riding a bike is a challenging activity. Therefore, cyclists are known to be vulnerable to low back pain. This is generally not very severe but can be the source of great frustration to the cyclist and the medical practitioner who is consulted to solve the clinical problem [1-3]. A study with professional road cyclists to register overuse injury indicated $86 \%$ of cyclists registered had an experience with overuse injuries. From the reported injuries; $45 \%$ were in the lower back, $23 \%$ in the knee and $11 \%$ in the neck. Only $23 \%$ of these injuries led to absence from training or competition [2].

Anecdotal evidences and studies of recreational cyclists also indicate anterior knee pain and lower back pain as common problems. Literature shows that knee injuries are most likely to cause time-loss from cycling, while lower back pain leads to the highest rates of functional impairment and medical attention $[4,5]$. Pain in the lower back and upper buttocks area is common in competitive cyclists. The combination of the severe forward leaning posture and the intense exertion of the muscles of the upper leg and gluteal puts constant squeezing pressure on the muscles and nerves in this area. Once inflammation develops it can be extremely difficult to get rid of for cyclists who train and/or compete daily. Not only is this condition painful, but it can also negatively affect performance as the body tries to protect the painful area by decreasing muscle activation. Even those who are tough enough to "pedal through the pain" may find that they are no longer able to race as fast or as far [6,7]. 
Cycling is a very popular sport all over the world. In each season cyclists use a variety of clothes. While each season's kit has different comfort requirements, hot summer (and cold winter) riding can be the most demanding. Most of the time they wear jerseys and cycling shorts, with different types of accessories [8,9]. The cycling jersey is usually worn with a tight fit in order to reduce air resistance. Jerseys are made from a material designed to wick moisture from the skin, keeping the cyclist cool and comfortable. Nevertheless, cycling sports jersey that is worn by bikers is different from other sportswear. It is well known for its prints and artistic style lines. But the style lines and prints only serve to promote the sponsors.

Cycling shorts are short \& skin-tight legwear designed to improve comfort and efficiency while cycling. It can compress the legs, which can help combat muscular fatigue with greater performance. It reduces wind resistance increasing aerodynamic efficiency, protects the skin against the repetitive friction with the bicycle seat, draws sweat away from the skin to prevent chafing and cools the rider down through the process of evaporation [10].

Cycling can be performed in many different weather conditions; thus, the expectations that people have from athletic apparel has increased. Athletic apparel must prevent excessive heat loss in cold weather and enable the release of sweat from the surface of the skin in hot weather [4]. Thermal resistance, air permeability, water vapor permeability and liquid water permeability have been suggested as critical properties for the thermal comfort of the clothes $[3,11]$.

The right clothing offers comfort, protection and performance. Different clothing is designed to suit different disciplines. Cycling sport is different from other sports. It has many features such as high energy consumption, high sweat rate and higher limb exercise and activity range than upper body. Being a high-strength outdoor sport, cyclists' motions generate much heat during cycling. Furthermore, as cycling sport is a long duration sport, cycling clothes should be not only functional but also must be comfortable while exercising for a long period (up to several hours). According to the characteristics of the cycling sports, cycling jerseys should adapt to the body movements in order to stretch and make the human body activity easy under the condition of satisfy the premise of clothing aesthetic effect. Furthermore, it should have other features such as an efficient mechanism to handle perspiration, a high moisture absorbency, heat preservation, windproof performance, resistance to sunlight and excellent washing performance [12].

Summer jerseys use synthetic fabrics, whilst winter jerseys sometimes feature wool such as merino. Cyclists look for jersey materials that provide good breathability and wicking to draw sweat away from the skin [13]. Experienced cyclists commonly wear matching compression shorts and jerseys while riding or racing [14]. This type of clothing is designed to optimize aerodynamics and comfort. City and commuter cyclists will need clothing that offers all-weather protection and visibility; road cyclists may look for an aerodynamic fit and specialist garment $[9,15]$.
The objective of this study was to assess whether a relationship exists between self-reported pain and cycling behavior (training volume, experience, the incidence of injuries, the prevalence of complaints, etc.) in the ability groups. Besides this, the study also aims to identify the potential injuries in cyclist and to establish the prevalence, both anatomical and discipline specific distribution, and severity of injury in elite/pro, recreational, amateur and junior cyclists.

Unlike previous studies, this paper not only identifies potential injuries but also looks into the satisfaction of the cyclists with the comfort of their current outfit. This can be used later to aid the development of a well fitted, comfortable cycling outfit that helps prevent prevalent injuries while satisfying the comfort desires of the wearer.

\section{Methods}

\section{Participants}

All level of cyclists was invited and divided in four cycling clusters; Junior: Men and women under 18 years old and cycling for competition; Elite: professional cyclists contracted by a team; Amateur: cyclists who do competition but are not professional or junior; and Others: recreational cyclists. For the purpose of this study, a total of 94 cyclists were recruited as any individual who cycled frequently.

\section{Survey}

A survey was developed and used to collect demographic information, training characteristics and comfort related information on the existing cycling outfits. Questions related to the aim of this paper were selected and are discussed in this paper.

\section{Data collection}

The online survey was distributed to cyclist club members via the Flanders cycling club's website in Belgium and via personal email. Voluntary return of the completed survey constituted participant consent. In many cases the questionnaire provided participants with a number of possible responses and participants were asked to choose the response that described their situation best.

\section{Statistical analysis}

The responses were collected, and data was analyzed using Statistical Package for the Social Sciences (SPSS) statistics software (SPSS V.21, IBM Corporation, New York, USA). The questionnaires returned by 94 subjects were included and statistical analysis was performed including descriptive methods and Chi-squared tests $(\chi 2)$. The level of statistical significance for $\chi 2$ analysis was set at $p=0.05$. To deduce whether the responses indicate a relationship between the variables (significant differences in expected frequencies), the p-values were examined. If the p-value of a parameter was greater than 0.05 ( $\mathrm{p}>0.05)$, not statistically significant relationship among the variables could be established, and it was not investigated further. 


\section{Results and Discussions}

The survey contained two parts, one specifically asking about potential injuries of cyclist and one about problems with their

Table 1: The response rate and characteristics of participants. current outfit. The response rate from each cluster is as follows: 50 recreational cyclists, 22 elite, 16 amateur and 6 juniors' cyclists (Table 1).

\begin{tabular}{|c|c|c|c|c|c|}
\hline & & \multicolumn{4}{|c|}{ Year of Cycling Experience } \\
\hline & & $<=5$ & $6-10$ & $11-20$ & $>=21$ \\
\hline \multirow{4}{*}{ Cycling cluster } & Recreational cyclist & 13 & 16 & 8 & 13 \\
\hline & Amateur cyclist & 3 & 5 & 5 & 3 \\
\hline & Junior cyclist & 5 & 1 & 0 & 0 \\
\hline & Elite cyclist & 14 & 5 & 2 & 1 \\
\hline \multirow{5}{*}{ Age range } & $<=18$ & 12 & 1 & 0 & 0 \\
\hline & $19-30$ & 10 & 8 & 2 & 0 \\
\hline & $31-40$ & 5 & 7 & 4 & 2 \\
\hline & $41-50$ & 5 & 8 & 4 & 5 \\
\hline & $>=51$ & 3 & 3 & 5 & 10 \\
\hline \multirow{2}{*}{\multicolumn{2}{|c|}{ Recreational cyclist }} & \multicolumn{4}{|c|}{ Cycling cluster } \\
\hline & & Amateur cyclist & Junior cyclist & Elite & \\
\hline \multirow{5}{*}{ Age range } & $<=18$ & 1 & 0 & 6 & 6 \\
\hline & $19-30$ & 4 & 2 & 0 & 14 \\
\hline & $31-40$ & 10 & 8 & 0 & 0 \\
\hline & $41-50$ & 16 & 4 & 0 & 2 \\
\hline & $>=51$ & 19 & 2 & 0 & 0 \\
\hline \multirow{2}{*}{ Gender } & Female & 11 & 4 & 0 & 3 \\
\hline & Male & 39 & 12 & 6 & 19 \\
\hline
\end{tabular}

Before proceeding with the analysis, we moved the two oldest respondents registered as elite (age range 41-50) to the recreational category, since from the data (low training volume) it can be assumed that they are retired elite.

\section{Cyclist characteristics and potential injuries}

Cyclist characteristics: In the study we took the following variables into account: age, gender, years of cycling experience, cluster (cycling level) and weekly cycling volume. This last was characterized by number of days, average hours, average speed and racing distance. From Table 1, we can see that there is a clear age bias in the data when divided in cluster. This is inherent to the definition of the clusters, where some are age based, and people cannot remain elite for their entire live. This reflects in the years of experience, where a cluster only open to young people cannot contain people with much experience, e.g. elite and junior mostly have less than 6 years of experience.

Table 2: Cycling intensity in relation to the age group.

\begin{tabular}{|c|c|c|c|c|c|c|c|c|}
\hline & & \multirow[t]{2}{*}{$\mathbf{N}$} & \multirow{2}{*}{ Mean } & \multirow[t]{2}{*}{ Std. Deviation } & \multicolumn{2}{|c|}{$\begin{array}{l}\text { 95\% Confidence Interval for } \\
\text { Mean }\end{array}$} & \multirow[t]{2}{*}{ Minimum } & \multirow[t]{2}{*}{ Maximum } \\
\hline & & & & & Upper Bound & Lower Bound & & \\
\hline \multirow{5}{*}{ Cycling volume days/week } & $<=18$ & 13 & 5.08 & 1.32 & 2.49 & 7.67 & 3 & 7 \\
\hline & $19-30$ & 20 & 5.26 & 1.52 & 2.28 & 8.25 & 2 & 6 \\
\hline & $31-40$ & 18 & 4.17 & 1.65 & 0.93 & 7.41 & 2 & 7 \\
\hline & $41-50$ & 22 & 2.55 & 1.34 & 0 & 5.18 & 1 & 5 \\
\hline & $>=51$ & 21 & 2.98 & 1.68 & 0 & 6.26 & 1 & 7 \\
\hline \multirow{5}{*}{ Avg. cycling hr. per week } & $<=18$ & 13 & 13.54 & 5.03 & 3.69 & 23.39 & 6 & 18 \\
\hline & $19-30$ & 19 & 15.05 & 5.2 & 4.86 & 25.25 & 4 & 18 \\
\hline & $31-40$ & 18 & 10.11 & 4.55 & 1.2 & 19.03 & 5 & 20 \\
\hline & $41-50$ & 21 & 7.29 & 4.83 & 0 & 16.75 & 3 & 20 \\
\hline & $>=51$ & 21 & 6.81 & 3.89 & 0 & 14.44 & 2 & 15 \\
\hline
\end{tabular}




\begin{tabular}{|c|c|c|c|c|c|c|c|c|}
\hline \multirow{5}{*}{ Speed (km/hr.) } & $<=18$ & 13 & 34 & 7.2 & 19.89 & 48.11 & 25 & 45 \\
\hline & $19-30$ & 20 & 36.08 & 6.78 & 22.79 & 85.08 & 25 & 44 \\
\hline & $31-40$ & 18 & 27.5 & 4.13 & 19.4 & 35.6 & 16 & 34 \\
\hline & $41-50$ & 22 & 26.93 & 2.56 & 21.91 & 31.95 & 22 & 34 \\
\hline & $>=51$ & 21 & 25.24 & 3.97 & 17.45 & 33.03 & 15 & 30 \\
\hline \multirow{5}{*}{ Distance $(\mathrm{km})$} & $<=18$ & 13 & 363.85 & 181.32 & 8.47 & 719.23 & 50 & 520 \\
\hline & $19-30$ & 20 & 403.75 & 172.91 & 64.85 & 742.65 & 60 & 520 \\
\hline & $31-40$ & 18 & 255 & 119.56 & 20.67 & 489.33 & 100 & 550 \\
\hline & $41-50$ & 22 & 163.41 & 128.11 & 0 & 414.51 & 28 & 600 \\
\hline & $>=51$ & 21 & 148.86 & 105.89 & 0 & 356.39 & 20 & 346 \\
\hline
\end{tabular}

Table 3: Descriptive statistics of cyclist characteristics.

\begin{tabular}{|c|c|c|c|c|c|c|c|c|c|c|c|c|c|}
\hline \multicolumn{14}{|c|}{ Descriptives } \\
\hline \multirow{2}{*}{\multicolumn{2}{|c|}{ Gender }} & \multicolumn{2}{|c|}{ Mean } & \multirow{2}{*}{$\begin{array}{l}\text { Std. } \\
\text { Devia- } \\
\text { tion }\end{array}$} & \multicolumn{2}{|c|}{$\begin{array}{l}95 \% \text { Confidence } \\
\text { Interval for Mean }\end{array}$} & \multirow{2}{*}{$\begin{array}{l}\text { Mini- } \\
\text { mum }\end{array}$} & \multirow{2}{*}{$\begin{array}{l}\text { Maxi- } \\
\text { mum }\end{array}$} & \multirow{2}{*}{$\begin{array}{c}5 \% \\
\text { Trimmed } \\
\text { Mean }\end{array}$} & \multirow{2}{*}{ Median } & \multirow{2}{*}{$\begin{array}{l}\text { Vari- } \\
\text { ance }\end{array}$} & \multirow{2}{*}{ Range } & \multirow{2}{*}{$\begin{array}{c}\text { Inter- } \\
\text { quartile } \\
\text { Range }\end{array}$} \\
\hline & & Statistic & $\begin{array}{l}\text { Std. } \\
\text { Error }\end{array}$ & & $\begin{array}{l}\text { Upper } \\
\text { Bound }\end{array}$ & $\begin{array}{l}\text { Lower } \\
\text { Bound }\end{array}$ & & & & & & & \\
\hline \multirow[t]{2}{*}{ Age } & Female & 41.33 & 3.244 & 13.763 & 34.49 & 48.18 & 20 & 76 & 40.59 & 42 & 189.412 & 56 & 19 \\
\hline & Male & 36.60 & 1.877 & 16.038 & 32.56 & 40.34 & 11 & 69 & 36.25 & 38 & 257.215 & 58 & 30 \\
\hline \multirow{2}{*}{$\begin{array}{c}\text { Cycling } \\
\text { experiance }\end{array}$} & Female & 9.83 & 2.252 & 9.556 & 5.08 & 14.59 & 2 & 40 & 8.59 & 6 & 91.324 & 38 & 8 \\
\hline & Male & 12.49 & 1.361 & 11.629 & 9.77 & 15.2 & 1 & 50 & 11.4 & 7 & 135.222 & 49 & 16 \\
\hline \multirow{2}{*}{$\begin{array}{l}\text { Cycling } \\
\text { volume } \\
\text { days per } \\
\text { week }\end{array}$} & Female & 3.78 & 0.461 & 1.957 & 2.8 & 4.75 & 1 & 7 & 3.75 & 3 & 3.83 & 6 & 4 \\
\hline & Male & 3.95 & 0.213 & 1.819 & 3.52 & 4.37 & 1 & 7 & 3.96 & 4 & 3.309 & 6 & 4 \\
\hline \multirow{2}{*}{$\begin{array}{c}\text { How many } \\
\text { hours a } \\
\text { week in } \\
\text { average }\end{array}$} & Female & 8.39 & 1.245 & 5.282 & 5.76 & 11.02 & 2 & 20 & 8.1 & 6.5 & 27.899 & 18 & 9 \\
\hline & Male & 10.78 & 0.661 & 5.65 & 9.46 & 12.1 & 2 & 20 & 10.81 & 10 & 31.924 & 18 & 13 \\
\hline \multirow{2}{*}{$\begin{array}{l}\text { Average } \\
\text { cycling } \\
\text { speed } \\
\text { (km/hr.) }\end{array}$} & Female & 24.72 & 1.066 & 4.522 & 22.47 & 26.97 & 15 & 33 & $24 . .80$ & 25 & 20.448 & 18 & 6 \\
\hline & Male & 30.88 & 0.761 & 6.506 & 29.36 & 32.39 & 20 & 45 & 30.66 & 28 & 42.325 & 25 & 8 \\
\hline \multirow{2}{*}{$\begin{array}{c}\text { Average } \\
\text { distance } \\
\text { per week } \\
\text { (in km) }\end{array}$} & Female & 195.83 & 36.171 & 153.462 & 119.52 & 272.15 & 25 & 550 & 185.65 & 132.5 & 23550.7 & 525 & 246 \\
\hline & Male & 279.11 & 20.385 & 174.168 & 238.47 & 319.75 & 20 & 600 & 278.18 & 250 & 30334.5 & 580 & 400 \\
\hline
\end{tabular}

Training intensity: We are interested in the possible difference in training intensity within a cluster due to age (Table 2). Do younger elite cyclist train harder than the older ones? Can the same conclusion be made for the recreational cyclists? To comment on these questions, we need to establish an indicator of training intensity. This should also give information on injuries and comfort. We investigate then the cycling intensity in relation to the age, sex and cluster (Table 3). We also look into the interactions among age, average cycling speed (km/hr), weekly training days, hours and distance.

Figure 1 shows average training volume per week (hour, days, speed and distance). From the point of view of intensity, it is clear that junior and amateur have a comparable intensity and are divisions which are purely based on age. Elite performed at higher intensity than other groups. On average, they cycle 5.64 days per week for $16.5 \mathrm{hrs}$ in total. The average weekly training days and distances of the clusters are depicted in Figure 1a and 1b respectively. As it is clearly shown in Figure 1, recreational cyclists reported lowest cycling intensity from all other groups in all cases.

We will use the cycled distance as a measure of training intensity and not the reported velocity because of the following. We check if the given weekly distance corresponds to the indicated weekly hours and average velocity. We calculate the control distance as the product of velocity and weekly hours. The control distance and the given distance are not normally distributed therefore we perform the Wilcoxon signed rank test to test if there is no difference in median between these two variables, $\mathrm{p}<0.001$.

From the test we obtain that the reported velocity by the correspondents is higher than the actual mean velocity they reach during training (Figure 2). This discrepancy is mainly due to the higher velocity reported by men in the elite and recreational groups. 


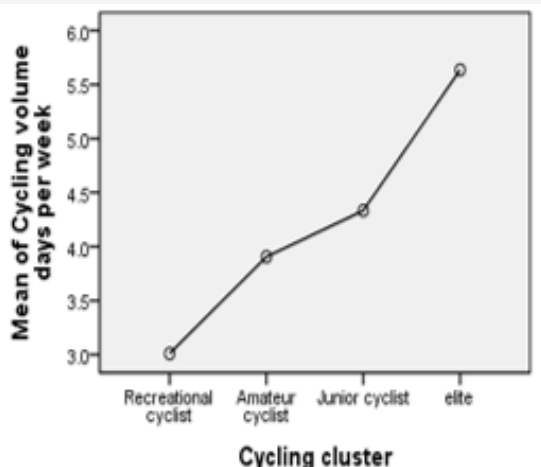

(a)

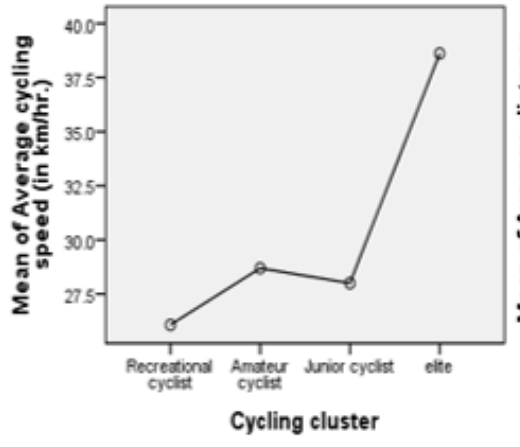

(c)

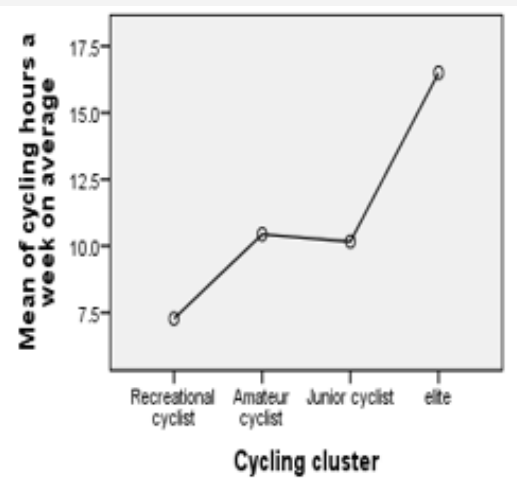

(b)|

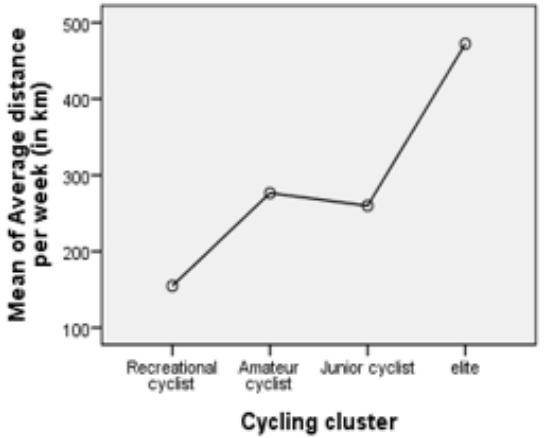

(d)

Figure 1: Mean plot graph of weekly volume training characteristics with the ability group: a) days, b) hours, c) speed and d) distances.

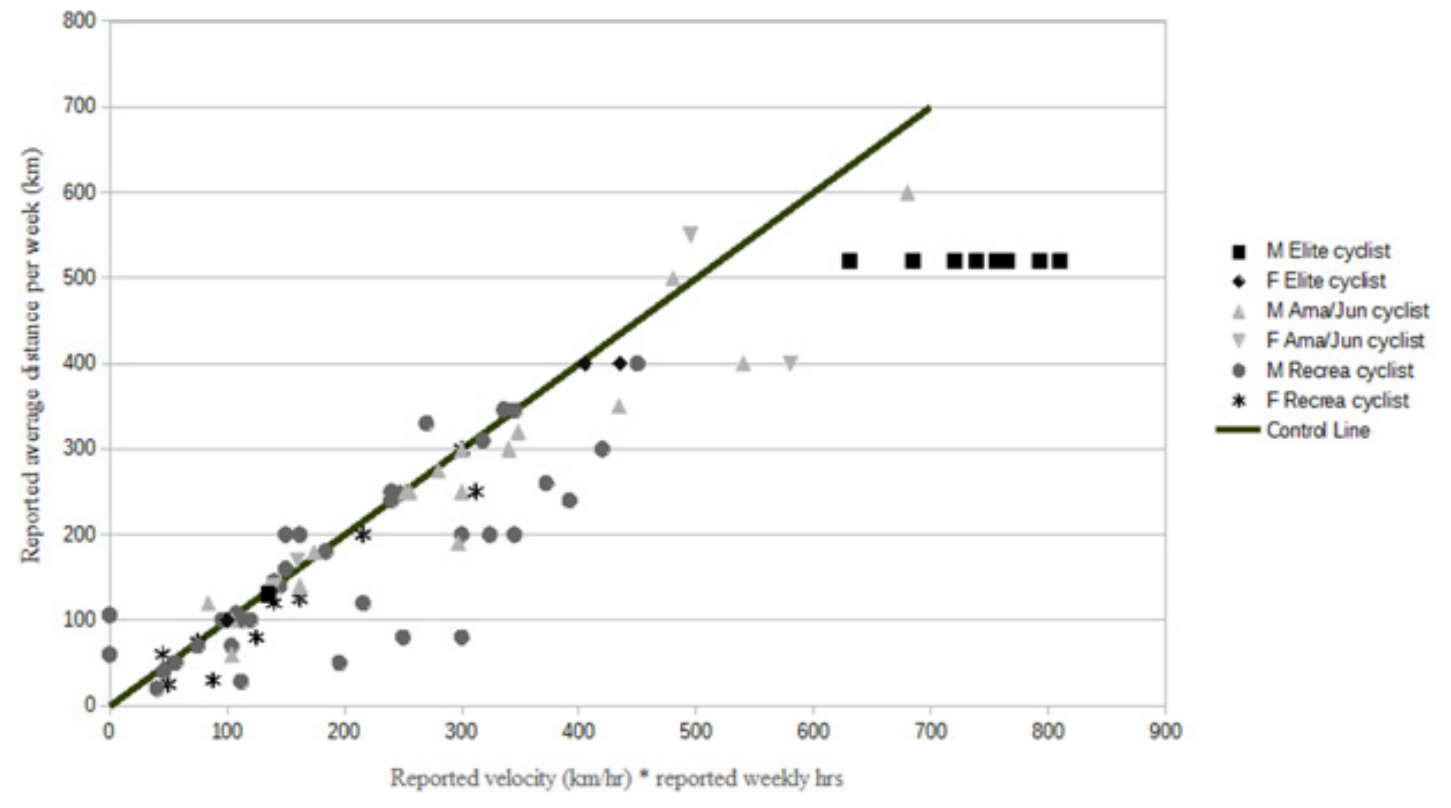

Figure 2: Normal scatter plot for reported average distance per week $(\mathrm{km})$ versus expected (observed) average distance per week ( $\mathrm{km})$.

We next analyse the relationship between age and distance. By analyzing the scatter dots, we have reason to exclude a possible linear or quadratic model relating age to distance. We consider cross tables of age nested within cluster versus distance. By performing Pearson Chi-square (Table 4), there is no statistical evidence that the distance is related to age within a cluster. We conclude that in a cluster, being older does not lead to less (or more) cycling.
Considering age versus training intensity, we find a statistically significant relationship between age group and average cycling speed $(\mathrm{km} / \mathrm{hr})$, and between age and weekly training days $(\mathrm{p}=$ $0.002)$, hours $(p=0.000)$ and distance $(p=0.000)$. This can be attributed to the fact that elite and junior cyclusts are overall younger. When they stop at older age and become amateur or recreational, their training intensity drops. Comparing between the 
clusters, as one would expect, the elite cyclists train significantly more than the other groups (Pearson Chi-squared test $\mathrm{p}=0.000$ ) (Table 5 and 6).

Table 4: Pearson Chi-Square Tests cluster versus age.

\begin{tabular}{|c|c|c|c|c|}
\hline & & & & Distance \\
\hline & & & Chi-square & 11.118 \\
\hline & Recreational & Age & $\mathrm{df}$ & 8 \\
\hline & & & Sig. & 0.195 \\
\hline & & & Chi-square & 8.6 \\
\hline & Amateur cyclist & Age & $\mathrm{df}$ & 9 \\
\hline Cycling cluster & & & Sig. & 0.475 \\
\hline & & A & Chi-square & 0.0 \\
\hline & Junior cyclist & & df & 0.0 \\
\hline & & & Sig. & 0.0 \\
\hline & & & Chi-square & 0.952 \\
\hline & Elite & Age & $\mathrm{df}$ & 1 \\
\hline & & & Sig. & 0.329 \\
\hline
\end{tabular}

Table 5: Distance in relation to the cluster group.

\begin{tabular}{|c|c|c|c|c|}
\hline \multicolumn{2}{|c|}{} & \multicolumn{3}{|c|}{ Distance } \\
\cline { 2 - 5 } & $<=150$ & $\mathbf{1 5 1}$ to 350 & $>=351$ \\
\cline { 2 - 5 } & Count & Count & Count \\
\hline \multirow{4}{*}{ Cycling cluster } & Recreational cyclist & 31 & 20 & 1 \\
\cline { 2 - 5 } & Amateur cyclist & 5 & 7 & 4 \\
\cline { 2 - 5 } & Junior cyclist & 1 & 4 & 1 \\
\cline { 2 - 5 } & Elite cyclist & 0 & 0 & 20 \\
\hline
\end{tabular}

Table 6: Pearson Chi-Square Tests distance versus cluster.

\begin{tabular}{|c|c|c|}
\hline \multirow{2}{*}{ Cycling cluster } & Chi-square & D3 \\
\cline { 2 - 3 } & $\mathrm{df}$ & 13.084 \\
\cline { 2 - 3 } & Sig. & 4 \\
\hline
\end{tabular}

Cycling injuries: Subjects were requested to give information about all pain/injuries they had experienced while cycling or after cycling. This resulted in 45.7\% (43/94) of the respondents indicating to suffer pain while cycling or immediately after cycling. About $19.15 \%$ of subjects perused medical assistance and $80.85 \%$ of subjects had been diagnosed with a serious injury at least once and had missed their training.

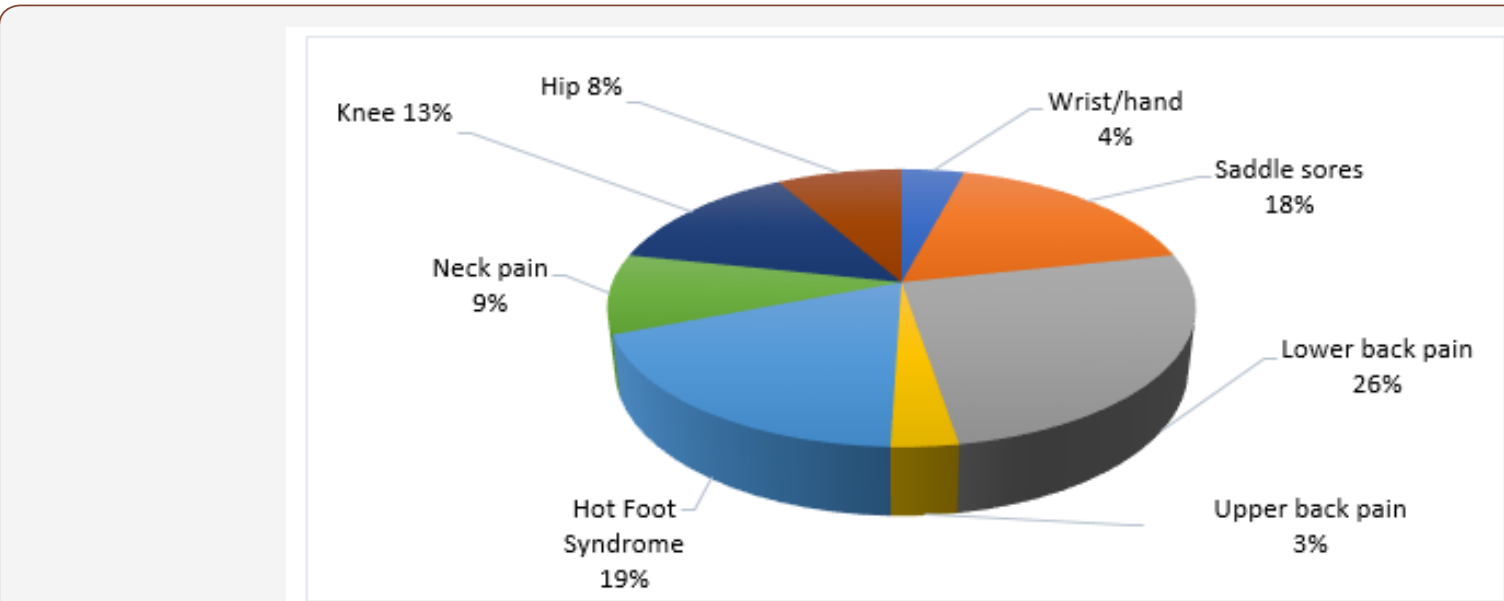

Figure 3: Most prevalent injury of cyclists.

The 43 respondents that reported to have pain, gave a total of 97 symptoms, Table 7. Most were lower back pain (26\%) followed by saddle sores (18\%), hot foot syndrome (19\%), knee pain (13\%),

Table 7: The most prevalent pain/injury for the ability group. neck pain (9\%), hip pain (8\%), wrist/hand and upper back pain (4\% \& 3\%), Figure 3.

\begin{tabular}{|c|c|c|c|c|c|c|c|c|c|}
\hline & \multicolumn{9}{|c|}{ Types of pain } \\
\hline Cycling cluster & Wrist/hand & $\begin{array}{c}\text { Saddle } \\
\text { sores }\end{array}$ & $\begin{array}{c}\text { Lower back } \\
\text { pain }\end{array}$ & $\begin{array}{c}\text { Upper back } \\
\text { pain }\end{array}$ & $\begin{array}{c}\text { Hot Foot } \\
\text { Syndrome }\end{array}$ & Neck pain & Knee & Hip & Total \\
\hline Recreational cyclist & 2 & 6 & 11 & 1 & 4 & 6 & 7 & 0 & 37 \\
\hline Amateur cyclist & 1 & 3 & 3 & 1 & 2 & 1 & 1 & 0 & 12 \\
\hline Junior cyclist & 0 & 1 & 2 & 0 & 1 & 0 & 0 & 0 & 4 \\
\hline Elite cyclist & 1 & 7 & 9 & 1 & 11 & 2 & 5 & 8 & 44 \\
\hline Total & 4 & 17 & 25 & 3 & 18 & 9 & 13 & 8 & 97 \\
\hline
\end{tabular}

The injured and uninjured counts in the cycling clusters were determined (Table 8). A Pearson Chi-Square-test between the two groups (injured and uninjured) was done. The results in Table 9 $(\mathrm{p}=0.007)$ indicate there is a relationship between being injured and cycling cluster. 
Table 8: The injured and uninjured counts in the cycling.

\begin{tabular}{|c|c|c|c|}
\hline \multicolumn{2}{|c|}{ Yes } & \multicolumn{2}{c|}{$\begin{array}{c}\text { Do you suffer from any } \\
\text { pain while cycling or } \\
\text { immediately after cycling? }\end{array}$} \\
\cline { 3 - 4 } \multicolumn{1}{|c|}{} & No & \\
\hline \multirow{3}{*}{ Cycling cluster } & Recreational cyclist & 19 & 33 \\
\cline { 2 - 4 } & Amateur cyclist & 6 & 10 \\
\cline { 2 - 4 } & Junior cyclist & 2 & 4 \\
\cline { 2 - 4 } & Elite cyclist & 16 & 4 \\
\hline
\end{tabular}

Table 9: Pearson Chi-Square Tests cluster versus injuries.

\begin{tabular}{|l|c|c|}
\hline & & $\begin{array}{c}\text { Do you suffer from any pain } \\
\text { while cycling or immediately } \\
\text { after cycling }\end{array}$ \\
\hline Cycling cluster & Chi-square & 12.042 \\
& df & 3 \\
\hline
\end{tabular}

Looking at the proportions we obtain Table 10. We can say that recreational cyclist typically cycles without pain while elite cyclist cycle with pain. No statistical evidence is found for difference in proportions in amateur or junior cyclists. Hence, it can be said that elite cyclists suffer more from extreme injuries than other groups. The possible reason is that they train at the most intensive level (Figure 1). Looking at the relationship between the age group and the level of injuries, we see that cyclists between 19-30 years old are injured more than cyclists younger than 18 years and older than 30 years $(p=0.003)$. This is again an effect due to the cluster with most injuries, elite, being in that age range. Lower back pain was the most prevalent overuse injury and caused the highest rates of functional damage and medical attention. Hip fracture, wrist/hand and upper back pain were classed as lower extremity injuries. The discipline in which injuries were sustained, as well as how much it was affected by the training characteristics and year of experience, was noted.
Table 10: Comparisons of column proportions.

\begin{tabular}{|c|c|c|c|}
\hline & & \multicolumn{2}{|c|}{$\begin{array}{l}\text { Do you suffer from any pain } \\
\text { while cycling or immediately } \\
\text { after cycling? }\end{array}$} \\
\hline & & Yes & No \\
\hline & & (A) & (B) \\
\hline \multirow{4}{*}{ Cycling cluster } & $\begin{array}{l}\text { Recreational } \\
\text { cyclist }\end{array}$ & & $\mathrm{A}(.046)$ \\
\hline & Amateur cyclist & & \\
\hline & Junior cyclist & & \\
\hline & Elite cyclist & $\mathrm{B}(.001)$ & \\
\hline
\end{tabular}

Despite that the vast majority of injuries are caused by an improper riding position of the rider, most prevalent injuries are generally due to overuse, and hence occur when a cyclist is riding too much or too fast. Further statistical analysis of the data proved this, we can say that the above most prevalent injuries are indeed generally due to overuse. Cycling a longer distance leads for recreational cyclists to more reported pain (Pearson Chi-Square test, p-value 0.036), while for the elite who all train a lot, 16 of the 20-report pain. The survey result proved that pain increases and affects cyclist that train at the most intensive level. It seems to be the case for all reported injuries that they become more prevalent with distance, but this is most pronounced for hot foot syndrome.

\section{Identified problems by cyclists with their outfit}

Apart from cyclists having problems with cycling due to injuries, they can also be affected by comfort issues with their sportswear. Knowing the minimum comfort characteristics of clothing is very important for the required application. In this study, the problems that cyclists experienced with their outfit were identified. This was assessed in terms of selected brands and their purchasing preference as well as outfit comfort including fit, breathability, amount of sweating and other causes of discomfort.

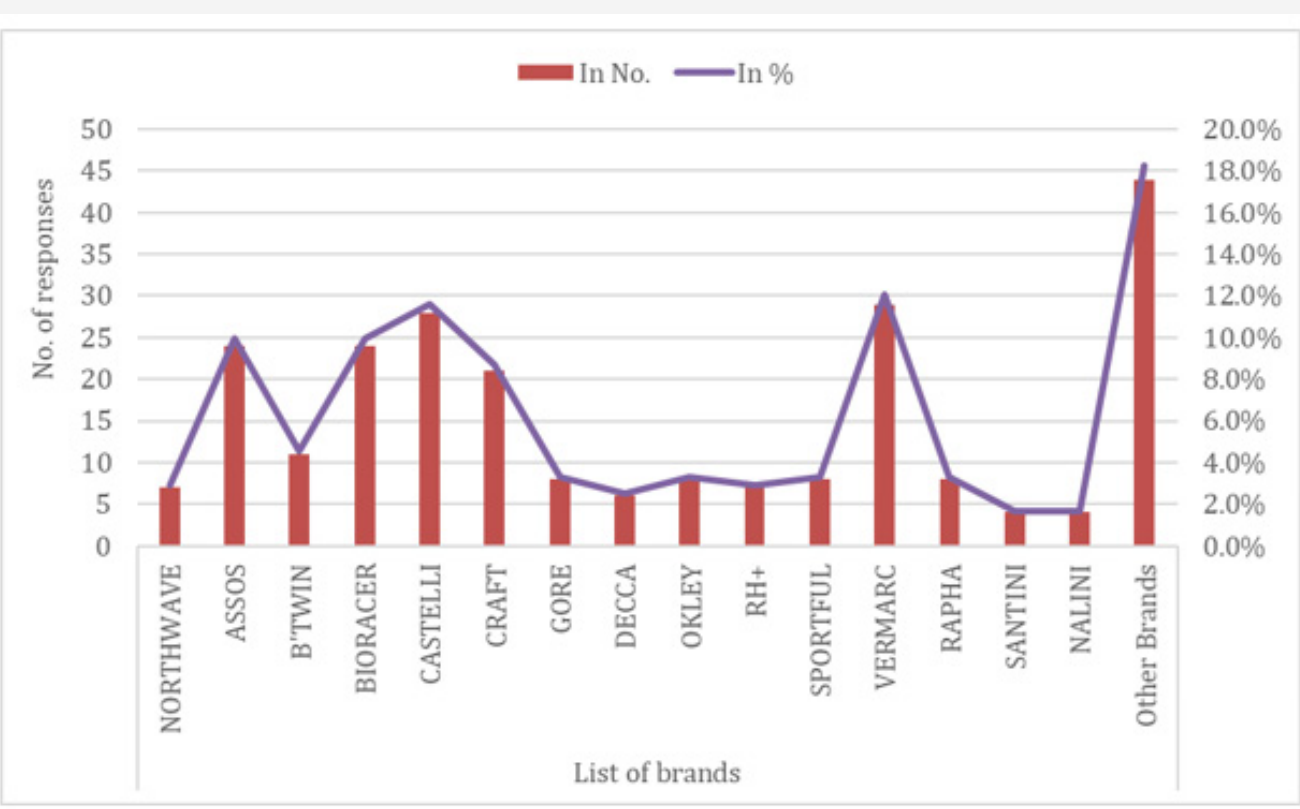

Figure 4: List of sportswear brands selected by Belgian cyclist. 


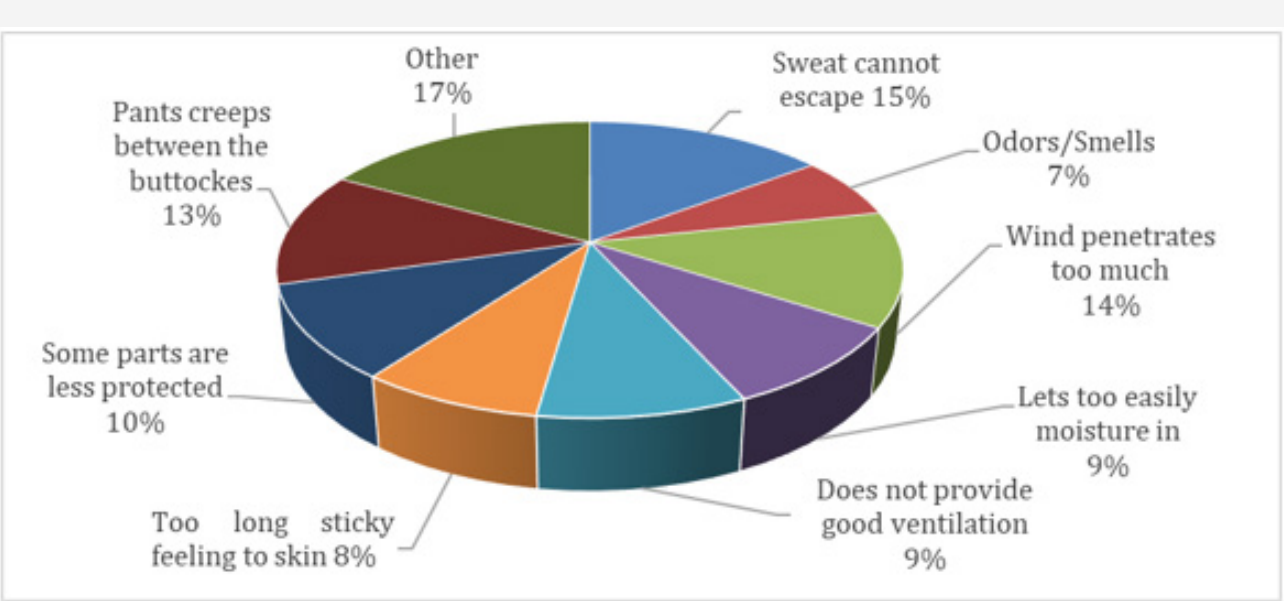

Figure 5: Cause of discomfort for the current outfit (type and frequency).

Customer survey and feedback help to improve the products and services, as well as to measure their level of satisfaction. Therefore, from the collected data the most frequently selected cycling outfit brands, their purchasing preference and problems with their outfit were analyzed (Figures 4\&5).

Vermarc (29), Castelli (28), Bioracer and Assoss (24) and Craft (21) were the most frequently selected brands by customers in the study (Figure 4). However, among 94 total respondents about $91 \%$ of cyclists said they were not loyal to a specific brand. Price, size fit, design, limited choice (availability), appearance/look and quality were the main reason for their selection preferences. It must be noted though that some respondents indicated they are sometimes forced to change their outfit due to sponsors, promotion and offers.

Cyclists were not satisfied with the comfort level of their current outfit (Figure 5). A total of 37 of cyclists experienced some discomfort sensation. Respondents identified their potential sources of discomfort and its effect on comfortability (including breathability and rate of sweating) while wearing these clothes. Most of the problems are connected with fabric characteristics, thermal and moisture discomfort sensation. However, design and fit of the garments were also identified as a potential source of discomfort.

Table 11: The relationship between size fit and breathability of the garment.

\begin{tabular}{|c|c|c|c|c|c|}
\hline \multirow{2}{*}{\multicolumn{2}{|c|}{ Size fit of the current cycling outfit }} & \multicolumn{3}{|c|}{$\begin{array}{l}\text { Is the moisture permeability (breathability) of your cyclist clothes } \\
\text { good enough? }\end{array}$} & \multirow[t]{2}{*}{ Total } \\
\hline & & Yes & No & Mostly & \\
\hline \multirow{2}{*}{ Excellent } & Count & 8 & 0 & 2 & 10 \\
\hline & Adjusted Residual & 1.8 & -1.8 & -0.3 & \\
\hline \multirow{2}{*}{ Very good } & Count & 19 & 0 & 7 & 26 \\
\hline & Adjusted Residual & 2.4 & -3.2 & 0.3 & \\
\hline \multirow{2}{*}{ Good } & Count & 22 & 6 & 9 & 37 \\
\hline & Adjusted Residual & 1 & -1.1 & 0 & \\
\hline \multirow{2}{*}{ Fair } & Count & 1 & 2 & 4 & 7 \\
\hline & Adjusted Residual & -2.1 & 0.4 & 2.1 & \\
\hline
\end{tabular}

Finding a balance between wind penetration and allowing sweat to escape is particularly challenging. As it is shown in Table 13, fit of the garment significantly affects its breathability. The respondents could choose good, not good and mostly good breathability, while fit was divided in 5 ranges. Based on a $\chi^{2-}$ analysis, there is a statistically significant relationship between the size fit of the garments and the breathability $(p=0.000)$. It seems that having a good fit and good breathability go hand in hand. This is probably due to the fact that the wicking needed to transport the sweat to the surface and also the thermal cooling by evaporation of sweat at the surface of the fabric both require good fit to function properly.

No relationship was found ( $p=0.168)$ between the amount of sweat and comfort experience (Table 11\&12). 53 of the respondents experienced little sweat, and out of these respondents only 12 subjects were not comfortable with this amount of sweating. Out of the total 94 respondents, 39 sweated a lot and 15 of them were uncomfortable with this amount of sweating. Though more sweating leads to more people who indicate a discomfort, the level of comfort was not found to be affected directly by the amount of sweating (Table 13). This could be because cyclists tolerate sweating as part of the sport, and cycling clothes are designed to handle high sweat rate. 


\begin{tabular}{|c|c|c|c|c|c|}
\hline \multirow{2}{*}{ Poor } & Count & 0 & 13 & 1 & 14 \\
\cline { 2 - 6 } & Adjusted Residual & -4.3 & 6.9 & -1.6 & \\
\hline \multirow{2}{*}{ Total } & Count & 50 & 21 & 23 & 94 \\
\hline
\end{tabular}

Table 12: Sweat assessment during cycling interrelated to respondent's comfort sensation.

\begin{tabular}{|c|c|c|c|c|c|}
\hline \multirow{2}{*}{\multicolumn{3}{|c|}{ Amount of sweat * Comfort experience }} & \multicolumn{2}{|c|}{$\begin{array}{l}\text { Do you experience this sweating as } \\
\text { uncomfortable? }\end{array}$} & \multirow{3}{*}{\begin{tabular}{|c|} 
Total \\
53 \\
\end{tabular}} \\
\hline & & & Yes & No & \\
\hline \multirow{6}{*}{$\begin{array}{l}\text { Do you sweat in your own cyclist } \\
\text { clothing while cycling? }\end{array}$} & \multirow{2}{*}{ Yes, I sweat a little } & Count & 12 & 41 & \\
\hline & & Adjusted Residual & -1.5 & 1.5 & \\
\hline & \multirow{2}{*}{ Yes, I sweat a lot } & Count & 15 & 24 & 39 \\
\hline & & Adjusted Residual & 1.8 & -1.8 & \\
\hline & \multirow{2}{*}{ No } & Count & 0 & 2 & 2 \\
\hline & & Adjusted Residual & -0.9 & 0.9 & \\
\hline Total & & Count & 27 & 67 & 94 \\
\hline
\end{tabular}

Table 13: Chi-Square Tests amount of sweat versus comfort experience.

\begin{tabular}{|c|c|c|c|}
\hline & Value & df & Asymp. Sig. (2-sided) \\
\hline Pearson Chi-Square & 3.57 & 2 & 0.168 \\
\hline Likelihood Ratio & 4.065 & 2 & 0.131 \\
\hline Linear-by-Linear Association & 1.241 & 1 & 0.265 \\
\hline N of Valid Cases & 94 & & \\
\hline
\end{tabular}

Based on a $\chi 2$-analysis, a statistical effect was found between reported distances cycled and the discomfort experience of cyclists with their clothing $(\mathrm{p}=0.035)$, where cyclists who train intensive (long distance) report less discomfort. In detail, of the 31 cycling more than $300 \mathrm{~km}$ per week, only 6 report wear discomfort. This shows that cycling a lot causes the cyclist to select much better outfits, though for $20 \%$ of those cyclists this is not yet sufficiently good. Further statistical analysis was done looking at the individual types of discomfort, and no dependence was found of those on distance. This indicates that of the $40 \%$ of cyclists that reported discomfort (almost 50\% for the recreational cyclists), the types of discomfort they report are for them a fixed problem with their cycling outfit and posture.

Generally, cycling clothes are multi-dimensional and performance oriented. It is crucial to know various factors that affect sports performance (i.e. garment, athlete preparation and intensity of the sport). It is also needed to know the frequent injuries that cyclists incur and design garments that offer protection, support and improve comfort particularly for professionals that train for several hours with their optimal speed and become susceptible to overuse injuries. Even though a number of clothing aids have been developed to assist with fatigue and to improve motor function and posture in athletes, the effectiveness of garment requirements for cycling sport are yet to be ascertained, including for compression garments.

Therefore, there is a rationale to do the above combined injurycomfort survey. The first part of the survey identified potential injuries and their possible causes, and the second part of the survey extracted problems on the current outfit and identified the perception of the users of their current cycling outfit. The research indicated that lower back pain, hot foot syndrome, saddle sores, and knee pain are common problems for recreational and elite cyclists. Currently, there are many kinds of cycling clothes on the sport wear market, however, the quality is uneven, and as a consequence especially recreational cyclists report discomfort while cycling. Two critical factors directly impacting the cycling clothes' quality (such as fabric properties and design) were identified. The results demonstrated that the cycling outfit should be selected depending on the cycling position and speed range in favor of the athletic performance. Depending on the nature of the sport, this methodology (i.e. investigating injury and comfort together) can be used as a basic design tool to optimize or select proper parameters for the betterment of sport outfits. Prior to making a new of outfit, this methodology can be an essential tool to investigate the performance of individual cases. A future study of the authors will entail the design and manufacture of an optimized prototype garment to minimize the injury level of cyclists as reported here while improving their perceived comfort.

\section{Conclusion}

From the analyzed data on the intensity, we can conclude that the elite cyclists train significantly more than the other groups. On average, they cycle 5.64 days per week for $16.5 \mathrm{hrs}$ in total. Junior and amateur have a comparable but somewhat lower intensity and are divisions which are purely based on age. Our results show that lower back pain is a common problem suffered by interviewed cyclists. The high prevalence of lower back pain in this study is consistent with previous investigations of professional and recreational cyclists and appears to confirm anecdotal reports that lower back pain is a common injury affecting competitive cyclists. The data shows that symptoms of lower back pain were mostly common among recreational and elite cyclists, with prevalence of $44 \%$ and $36 \%$ respectively. Saddle sores and hot foot syndrome were the second most prevalent pain and there was a low prevalence of upper back pain. From the results we can conclude that lower back pain is one of the injuries which may potentially lead to cyclist absence from training or competition. However, it could be speculated that elite cyclists have, by this stage in their 
cycling career, either adjusted their bicycle position to minimize discomfort on upper body anatomy/shape or physically adapted to the ergonomic demands of the sport.

Concerning current cycling outfits, we found that many cyclists were not satisfied with the comfort level of their current outfit, especially among the recreational cyclists. Discomfort features were design, breathability and handling of sweating during cycling, although most cyclists did not experience the last as discomfort. It seems that good fit and good breathability go hand in hand. Though elite cyclists report much less discomfort, at $20 \%$ this still remains high, therefore there is a need to improve the existing cycling outfits and prioritize better design to improve fit. Moreover, it should be investigated if lower back pain can be attenuated or prevented by adapted cycling outfits, even though our survey results indicate that they are mainly due to overuse.

In addition to the current approach, physiological and wearer trial measurements would be essential to quantify the effectiveness of the current outfits so as to provide a well-informed strong platform in the design and development of functional cycling garments.

\section{Funding}

This research work was carried out in the frame of the HGPP project (International University Partnership Services for the Establishment of Postgraduate Programs in Ethiopia) funded through GIZ GmbH under a grant number 11.2216.7/002.01.

\section{Acknowledgements}

The authors would like to thank the VLAIO under grant number AIO.TET.2016.0004.01 (TETRA HBC.2016.0079) for partial financial support. We also give special thanks to Mr. J Cools (University College Ghent) for his assistance with the participant while doing the survey and Dr. J Shuermans (Department of Rehabilitation Sciences and Physiotherapy, UGent) for her professional comments and feedback.

\section{Conflict of Interest}

Authors declare no conflict of interest.

\section{References}

1. Chapman AR, Vicenzino B, Blanch P, Knox JJ, Dowlan S, et al. (2007) The influence of body position on leg kinematics and muscle recruitment during cycling. Journal of Science and Medicine in Sport 11(6): 519-526.

2. Clarsen B (2009) Overuse Injuries in Professional Road Cyclists. Master's Thesis in Sports Physiotherapy. Norwegian School of Sports Science: $1-79$.

3. Savelberg HH, Van de Port IG, Willems PJ (2003) Body configuration in cycling affects muscle recruitment and movement pattern. Journal of Applied Biomechanics 19(4): 310-324.

4. Dahlquist M, Leisz M, Finkelstein M (2015) The Club-Level Road Cyclist: Injury, Pain, and Performance. Clin J Sport Med 25(2): 88-94.

5. Schwellnus MP, Derman EW (2005) Common injuries in cycling: Prevention, diagnosis and management. SA Fam Pract 47(7): 14-19.

6. Kuo CS, Hu HT, Lin RM, Huang KY, Lin PC, et al. (2010) Biomechanical analysis of the lumbar spine on facet joint force and intradiscal pressure-a finite element study. BMC Musculoskelet Disord 11: 151.

7. Silberman MR (2013) Bicycling injuries. Curr Sports Med Rep 12(5): 337-345.

8. Venkatraman PD, Tyler DJ (2013) Performance of compression garments for cyclists. In the Textile Institute's International Conference on Advances in Functional Textiles, Manchester, UK, pp. 1-32.

9. Kun Z, Yanzhen W (2015) Research on Bicycle Riding Clothes. Science Research 3(5): 252-255.

10. Luo S, Wang J, Shi H, Yao X (2015) A novel approach to characterize dynamic pressure on lower limb wearing compression cycling shorts. Journal of the Textile Institute 107(8): 1004-1013.

11. Dorel S, Couturier A, Hug F (2009) Influence of different racing positions on mechanical and electromyographic patterns during pedalling. Scand J Med Sci Sports 19(1): 44-54.

12. Qiu Chunyan, HU Yue (2015) Design of outdoor sports monitoring function cycling jerseys. European Journal of Business and Social Sciences 4(2): 180-189.

13. Rob Simpson (2016) How to choose the best cycling jersey for you cycling jerseys explained.

14. Lovell DI, Mason DG, Delphinus EM, McLellan CP (2011) Do compression garments enhance the active recovery process after high-intensity running? J Strength Cond Res 25(12): 3264-3268.

15. Spurkland L, Bardal LM, Sætran L, Oggiano L (2015) Low aerodynamic drag suit for cycling - design and testing. In 3rd International Congress on Sport Sciences Research \& Technology support, Europe, pp. 89-96. 